\title{
O JOGO ENTRE REAL E FICCIONAL EM ANTONIO TABUCCHI
}

Melissa Cobra Torre*

RESUMO: O jogo literário é recorrente na obra do escritor italiano Antonio Tabucchi. Este se dá na construção da própria narrativa através de jogos de espelho e inversões de identidade dos personagens. A partir da relação estabelecida entre 0 conto "A frase a seguir é falsa. A frase anterior é verdadeira" e o romance Noturno Indiano, o escritor italiano busca confundir o leitor, levando-o a acreditar na veracidade dos fatos narrados em seus textos. Isso faz com que as identidades do protagonista de Noturno Indiano e do personagem de "A frase a seguir é falsa. A frase anterior é verdadeira" que assina como Antonio Tabucchi se sobreponham. Esse aspecto faz parte do jogo entre real e ficcional estabelecido pelo autor, o qual procura induzir o leitor a acreditar que tais personagens são a representação do próprio escritor dentro de seus textos.

PALAVRAS-CHAVE: jogo literário; real; ficcional; Antonio Tabucchi.
* melissactorre@yahoo.com.br

Doutoranda em Letras: Estudos Literários pela UFMG. Mestre em Letras: Estudos Literários também pela UFMG.

RESUMEN: El juego literario es recurrente en la obra del escritor italiano Antonio Tabucchi. Este se da en la construcción de la propia narrativa a través de juegos de espejos e inversiones de identidad de los personajes. A partir de la relación establecida entre el cuento "La frase a seguir es falsa. La frase anterior es verdadera" y el romance Nocturno Indiano, el escritor italiano busca confundir el (al) lector, llevándolo a creer en la veracidad de los hechos narrados en sus textos. Eso lo hace con las identidades sobrepuestas del protagonista de Nocturno Indiano y del personaje de "La frase a seguir es falsa. La frase anterior es verdadera" que firma como Antonio Tabucchi. Ese aspecto hace parte del juego entre lo real y lo ficcional establecido por el autor procurando inducir al lector a creer que tales personajes son la representación del propio escritor dentro de sus textos.

PALABRAS CLAVE: Juego literario; real; ficcional; Antonio Tabucchi. 
1. ARRIGUCCI JUNIOR. O escorpião encalacrado, p. 168.

2. ARRIGUCCI JUNIOR. O escorpião encalacrado, p. 168.

3. ARRIGUCCI JUNIOR, 1973: 168.

4. PERRONE-MOISÉS. Lição de casa, p. 83.
Os processos de construção textual têm sido objeto de indagação pela crítica literária. Dessa forma, é possível retomar um dos aspectos teóricos que associa a ficção ao jogo. Para Davi Arrigucci Jr., "em diversas épocas da história da literatura, sobretudo em momentos de transição ou crise de um determinado código ou sistema técnico-expressivo, se fez patente o jogo literário, através do desmascaramento irônico dos procedimentos de construção da obra" ${ }^{1}$. Sendo assim, "a literatura procura hoje se desfazer de sua máscara, perguntando por si mesma, buscando a si mesma, apresentando seu próprio jogo como principal espetáculo"2. Isso revela

a tendência da literatura para adquirir uma aguda consciência de si própria (um ver-se fazendo que tornará, muitas vezes, sua realização problemática), para se apresentar enquanto tal, para denunciar suas próprias convenções, explicitar as regras do jogo, indagando acerca de seu próprio ser ${ }^{3}$.

No posfácio de Aula, Leyla Perrone-Moisés ressalta a importância do jogo para a teoria de Barthes. O conceito está ligado ao teatro e ao fingimento, sendo que "o fingimento, a encenação, são os únicos meios de o sujeito se processar na escritura”".

Ao refletir sobre a questão do jogo na obra de Haroldo Maranhão, em sua tese Fios da Memória, jogo textual e ficcional de Haroldo Maranhão, Sérgio Afonso Alves reporta-se aos escritos de Barthes e Arrigucci Jr. Sob essa perspectiva, o autor evidencia que a teoria de Barthes sobre o jogo estrutura-se em torno de dois aspectos fundamentais: teimar e deslocar. Em relação ao primeiro elemento, Sérgio Alves aponta que, de acordo com o pensamento do semiólogo francês, o escritor não deve se colocar como "o mantenedor ou o servidor de uma arte, mas se posicionar na encruzilhada de todos os discursos, se manter contra tudo, teimar a força de uma de-

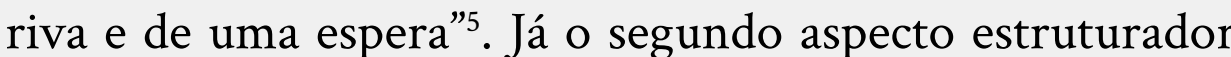
da teoria de Barthes a respeito do jogo refere-se à ideia de "transportar-se para onde não se é esperado, ou ainda e mais radicalmente, abjurar o que se escreveu (mas não, forçosamente, o que se pensou), quando o poder gregário o utiliza e serviliza"6. O escritor precisa, portanto, posicionar-se criticamente diante de sua própria produção.

Quanto ao estudo de Davi Arrigucci Jr. sobre o jogo na obra de Julio Cortázar, Sérgio Alves salienta que este se dá a partir de um movimento escorpióide, no qual o texto dobra-se sobre si mesmo e enrosca-se diversas vezes, "tocando em pontos distantes para depois retornar ao local de partida, como se houvera a intenção de criar espaços que não se esgotam em si, mas se necessitasse ir sempre além para abordar um sentido esquecido do signo"7. Ainda com base nas considerações do autor de $O$ escorpião encalacrado, Sérgio Alves mostra que o desdobramento do texto sobre si mesmo "é responsável pelos motivos recorrentes que constituirão as vias
5. ALVES. Fios da memória, jogo textual e ficcional de Haroldo Maranhão, p. 109.

6. BARTHES apud ALVES. Fios da memória, jogo textual e ficcional de Haroldo Maranhão, p. 109.

7. ALVES. Fios da memória, jogo textual e ficcional de Haroldo Maranhão, p. 110
EM TESE
BELO HORIZONTE
v. 19
N. 3
SET.-DEZ. 2013
TORRE. 0 jogo entre real e ficcional em Antonio Tabucchi
P. $148-158$ 
8. ALVES. Fios da memória, jogo textual e ficcional de Haroldo Maranhão, p. 111. de acesso - os vasos comunicantes - que proporcionarão a abertura para atingir o acesso à 'outra' realidade".

No romance Noturno Indiano, do escritor italiano Antonio Tabucchi, o jogo pode ser percebido na própria construção textual, a partir de espelhamentos e inversões de identidades. A narrativa estrutura-se em torno da busca de Roux por seu amigo Xavier, supostamente perdido na Índia. Na tentativa de encontrar o amigo, o protagonista segue falsas pistas e indícios incongruentes deixados por Xavier. Com isso, embrenha-se pelos labirintos de uma Índia enigmática e misteriosa.

Ao longo da narrativa, podemos perceber que, ao buscar o amigo, era a si mesmo que Roux procurava. Nesse sentido, os dois personagens são a imagem especular um do outro Ambos são, ao mesmo tempo, semelhantes e opostos, apresentando uma relação de complementação e antagonismo. É esse jogo de espelhos estabelecido entre Roux e Xavier que nos permite afirmar que tais personagens constituem o par único/duplo.

O jogo em Noturno Indiano pode ser percebido em diversos níveis, inclusive na própria estrutura narrativa. Um exemplo disso é a intrigante cena final do romance, em que Roux pede a Christine, que o acompanhava em um jantar, que ela imaginasse ser ele um escritor que, naquele momento, está escrevendo um livro. Ao narrar à sua acompanhante história desse suposto romance, reconta toda sua trajetória pela Índia até aquele ponto da narrativa. Entretanto, ao fazê-lo, coloca-se no lugar de Xavier, assumindo a perspectiva do perseguido e não do perseguidor.

É nesse sentido que o livro, supostamente escrito por Roux, coincide com o romance de Antonio Tabucchi que o leitor tem em mãos, sendo este, no entanto, narrado segundo uma perspectiva invertida. É nesse movimento, em que a narrativa volta-se sobre si mesma, que o jogo é instaurado, fazendo com que o personagem Roux e o autor se confundam, pois resta a sugestão de que Antonio Tabucchi seja ele próprio o protagonista de seu romance: "suponhamos que eu esteja escrevendo um livro". No entanto, ao inserir seu discurso em uma esfera hipotética, o protagonista deixa em aberto todas as possibilidades apontadas anteriormente em relação à coincidência entre autor e personagem, sendo mesmo impossível sustentar afirmações incondicionais ou verdades absolutas. Dessa forma, o que a narrativa de Noturno Indiano faz é prender o leitor em um labirinto do qual este jamais poderá sair sem a certeza da dúvida.

O mundo presente nas obras de Antonio Tabucchi é o espaço em que real e ficcional se encenam, por meio de um jogo constante. No que se refere à temática da viagem, podemos perceber, mais uma vez, o jogo entre realidade e ficção proporcionado por Antonio Tabucchi. Em Noturno Indiano, 
o protagonista recorre diversas vezes ao guia de viagens India: a travel survival kit para orientar-se não só pelas cidades por onde passa, como também pela cultura indiana. Esse livro, publicado pela Lonely Planet Publications, apresenta ao leitor uma visão alternativa da Índia em contraposição aos roteiros turísticos tradicionais que buscam transmitir a imagem de uma Índia exótica e exuberante. Trata-se de um guia feito por uma equipe anglo-indiana de viajantes profissionais e contém informações preciosas sobre a vida prática de um viajante, sendo um suporte real de viagens. ${ }^{10}$

Esse livro constitui-se, portanto, em uma importante fonte de conhecimento sobre a Índia tanto para o protagonista quanto para o autor. As várias referências ao guia de viagens que podem ser encontradas, no decorrer do texto de Tabucchi, são justamente o elemento que permite ao autor traçar um trajeto possível pela Índia, o qual poderia ser seguido por um eventual viajante que pretendesse aventurar-se por aqueles caminhos. Para isso, no início de Noturno Indiano, em uma seção intitulada "Índice dos lugares deste livro", o escritor enumera os locais, por sinal existentes, por onde seu protagonista passa durante seu percurso.

A partir de tais considerações, é importante ressaltar não apenas o fato de Antonio Tabucchi deixar claro que faz uso de um guia de viagens como referência para a construção de seu texto, como ainda insere várias citações retiradas deste em seu Noturno Indiano. Isso confirma o caráter de real que o escritor busca transparecer em seu livro, chegando a afirmar que ele próprio seria o protagonista de Noturno Indiano, tendo também percorrido o mesmo trajeto de seu personagem. Essa afirmação está presente na nota introdutória do romance, em que diz: "eu também tive de percorrer os mesmos lugares que o protagonista desta história percorreu"11. Quando perguntado em uma entrevista ao jornal Corriere della sera sobre a veracidade de sua viagem à Índia, Antonio Tabucchi confirma:

Notturno Indiano è un libro che, sotto molti e importanti aspetti, è direttamente autobiografico (io ho fatto quel viaggio in India, io ho visitato quei luoghi, io ho compiuto quel percorso, l'io narrante di Noturno Indiano, che per tutto il libro dice "io", sono io, o lo sono stato in un determinato momento della mia vita). ${ }^{12}$

Dessa forma, o autor busca confundir o leitor, envolvendo-o em uma trama na qual não consegue mais discernir o que é real daquilo que não é. Quando declara que a viagem narrada em Noturno Indiano trata-se de um percurso real, Antonio Tabucchi joga com o leitor. As notas e prólogos de seus textos, ao invés de fornecerem explicações que clarifiquem a narrativa a que se referem, acabam por aumentar ainda mais a dúvida que geralmente se impõe ao final de suas obras.
11. TABUCCHI. Noturno Indiano, p. 7.

12. TABUCCHI Apud DOLFI, 2006:76. "Noturno Indiano é um livro que, sob vários e importantes autobiográfico (eu fiz aquel viabiografico leu fiz aquela vigem para a lndia, eu visitei (a) Noturno Indiano, narrador de olurno liz'su', que por todo em um determina u momi eu minha vida)." (Tradução nossa). 
A esse respeito, salientamos que nossa intenção não é, em absoluto, entrar em uma discussão quanto à veracidade ou não da viagem de Antonio Tabucchi à Índia, a qual teria resultado na composição de seu romance. O que pretendemos é atentar para o fato de que, se consideramos a narrativa de Antonio Tabucchi como unicamente produto de uma viagem imaginária ou textual, podemos perder uma outra dimensão da obra em questão que é aquela em que se dá a tensão entre real e ficcional. Com efeito, chegando a uma conclusão definitiva de que Noturno Indiano trata de uma viagem que se dá apenas através da linguagem, ignoramos todo o esforço do autor em construir aquela tensão entre real e ficcional, a qual tem como intenção criar a suspeita no leitor quanto à veracidade ou não dos fatos narrados.

Desse modo, não é à toa que o autor mune seu protagonista de um guia real de viagens e enumera lugares realmente existentes, no início da narrativa. Nos textos de Antonio Tabucchi, o enigma e a dúvida sempre estarão presentes devido a essas estratégias de ficcionalidade utilizadas pelo autor, as quais provocam ora certeza, ora incerteza no leitor.

Para tornar a ficção mais complexa, Roux afirma que Xavier é um escritor. Esse dado reforça o argumento de que Roux e Xavier são não apenas a imagem especular um do outro, mas também a possível representação do próprio autor dentro de sua obra. Essa sugestão também está dada no conto "A frase a seguir é falsa. A frase anterior é verdadeira"13, de Antonio Tabucchi, presente no livro Os voláteis do beato Angélico ${ }^{14}$

No conto mencionado, Antonio Tabucchi (personagem) escreve, em uma de suas cartas a Xavier, que "os escritores são, frequentemente, pessoas nas quais não podemos confiar até quando afirmam praticar o mais rigoroso realismo. Pelo que me diz respeito, mereço, portanto, a máxima desconfiança" ${ }^{15}$. Dessa forma, o leitor é envolvido em uma narrativa na qual real e ficcional se encenam, sendo gerados na trama textual. Diante da complexidade da ficção, o leitor entra nessa dimensão lúdica do universo tabucchiano, embrenhando-se por seus labirintos repletos de espelhos e sombras e mantendo-se, no entanto, dentro e fora do jogo.

Sob essa perspectiva do jogo, Noturno Indiano sugere uma reflexão sobre o próprio ato de narrar. Existe uma leitura possível do romance de Antonio Tabucchi como a busca do escritor pela própria narrativa. O fato de Xavier e Roux serem supostos escritores corrobora a ideia de que existe uma dimensão metalinguística dentro do romance, dedicada à reflexão crítica do próprio fazer literário. Isso se deve ao fato de ocorrer, em Noturno Indiano, uma busca da construção da narrativa, a qual se dá de forma simultânea à procura de Roux por Xavier.

O livro de Antonio Tabucchi parece configurar-se como a narrativa da busca de uma narrativa, a qual, no entanto,
13. Título original: “La frase che segue è falsa. La frase che precede è vera".

14. Título original: / volatili del beato Angelico.

15. TABUCCHI. A frase a seguir é falsa. A frase anterior é verdadeira, p. 53. 
permanece em aberto devido à impossibilidade de se encontrarem soluções para seu desfecho. Esse aspecto pode estar relacionado à convicção de que o sujeito é incapaz de entrar em contato com o real absoluto e com a essência das coisas. Nesse sentido, é impossível ao indivíduo alcançar a verdade.

Em O escorpião encalacrado, Davi Arrigucci Jr. comenta sobre a busca da narrativa na obra de Julio Cortázar, palavras que poderiam muito bem ser estendidas à obra de Antonio Tabucchi em questão:

A exigência de se atingir o que as palavras não podem dizer acaba por exigir também a tematização do próprio ato de narrar, ou melhor, da sua possibilidade. É como se a narrativa se tornasse uma narrativa em busca da sua própria essência, centrando-se sobre si mesma. A narrativa de uma busca se faz uma busca da narrativa. Ao tematizar uma busca essencial, tematiza-se a si própria. ${ }^{16}$.

Em Antonio Tabucchi, a própria construção textual da narrativa aponta para o jogo. A busca incessante de Xavier empreendida por Roux, em Noturno Indiano, comprova isso. Essa pode ser lida como a atitude do escritor que se debruça sobre a própria obra, refletindo sobre esta de forma crítica Essa faceta do lúdico, na obra de Antonio Tabucchi, aponta para uma experiência potencialmente reveladora de outras dimensões do real, que se constrói pelo jogo de ilusões.
No conto "A frase a seguir é falsa. A frase anterior é verdadeira”, são apresentadas ao leitor quatro cartas trocadas reciprocamente por Antonio Tabucchi - fazendo-se, portanto, personagem - e Xavier Janata Monroy, o qual se apresenta como o membro da Sociedade Teosófica com quem Roux trava um diálogo no sexto capítulo de Noturno Indiano.

Ao assinar as referidas cartas, Antonio Tabucchi ficcionaliza a si mesmo, assumindo-se como personagem do conto epistolar. Além disso, confirma que fez uma viagem à Índia, fornecendo, inclusive, alguns detalhes da mesma, como sua visita ao templo de Shiva Horripilante, o qual teria fotografado, mesmo sendo a entrada no local interditada a não hinduístas. Tais aspectos sugerem que o protagonista de Noturno Indiano seria uma representação do próprio Antonio Tabucchi no interior da obra. No romance, não nos é fornecido o nome do protagonista, mas apenas o seu apelido Roux - o que deixa sua identidade em aberto. Para aumentar as suspeitas do leitor sobre a correspondência entre autor e personagem, Antonio Tabucchi afirma ter conhecido o interlocutor de sua correspondência na Sociedade Teosófica, local que o personagem Roux visita em busca de pistas sobre seu amigo Xavier. O autor de Noturno Indiano teria pedido licença a Xavier Monroy para usar alguns de seus traços na composição de um personagem, o que resultou na criação, nas palavras de Tabucchi, do "romanesco [...] teósofo de

EM TESE

BELO HORIZONTE

v. 19

N. 3

SET.-DEZ. 2013

TORRE. 0 jogo entre real e ficcional em Antonio Tabucchi

P. $148-158$ 
17. TABUCCHI. A frase a seguir é falsa. A frase anterior é verdadeira, p. 53
Madras"17. Nesse sentido, tais indicações consistem em pistas lançadas pelo escritor italiano, essenciais ao jogo entre o real e a ficção.

Tratando-se de um jogo, devemos ter em mente que quem assina as cartas de "A frase a seguir é falsa. A frase anterior é verdadeira" não é o autor empírico, mas Antonio Tabucch ficcionalizado. É nessa medida que se torna possível a sugestão da existência de uma sobreposição entre Roux (protagonista de Noturno Indiano) e Antonio Tabucchi (personagem que assina as cartas do conto epistolar). No entanto, a intenção do autor parece ser, de todo modo, confundir o leitor ao conduzi-lo por esse emaranhado de sugestões, fazendo com que este tome por real a correspondência trocada com o teósofo de Madras e, consequentemente, a narrativa de Noturno Indiano.

Também é nesse contexto que será fornecido o fato mais curioso desse jogo, então estabelecido: a similaridade entre os nomes do membro da Sociedade Teosófica e do amigo de Roux, Xavier Janata Pinto, perdido na Índia. Na primeira da série de cartas, Xavier Janata Monroy comenta, inclusive, sobre o fato de Antonio Tabucchi ter utilizado seu nome no romance, mesmo sendo de forma camuflada. Esclarece, ainda, que, em sua última viagem à Europa, teria comprado um exemplar de Noturno Indiano, bem como alguns jornais contendo críticas ao mesmo. Pretendia, com isso, verificar que fim havia levado a história que Antonio Tabucchi estava escrevendo na Índia, a qual resultou em um romance. Sua curiosidade justifica-se pelo fato de que o escritor italiano teria visitado a Sociedade Teosófica em Madras e, ainda, revelado ao teósofo que estava à procura de uma pessoa ao mesmo tempo em que escrevia um "pequeno diário indiano"18.

O fato de Antonio Tabucchi revelar ao teósofo de Madras que estava à procura de alguém na Índia faz com que o leitor se pergunte qual a relação entre a pessoa procurada pelo escritor italiano e o amigo buscado incessantemente por Roux em Noturno Indiano. Além disso, os escritos de Antonio Tabucchi, que resultariam no romance em questão, são referidos em "A frase a seguir é falsa. A frase anterior é verdadeira" como pertencentes a um diário, o que nos remete à sugestão de uma autobiografia. Tais afirmações são outras peças desse quebra-cabeça, constituindo-se como mais algumas pistas de que Roux representaria o próprio autor do romance no interior de sua obra. No entanto, salientamos, mais uma vez, que esses indícios da equivalência entre Antonio Tabucchi e o protagonista de Noturno Indiano fazem parte do jogo entre o real e a ficção estabelecido pelo escritor italiano, o qual pretende confundir o leitor, fazendo com que este tome por real o romance Noturno Indiano, bem como a correspondência trocada entre Tabucchi e o teósofo de Madras.
18. TABUCCHI. A frase a seguir e falsa. A frase anterior verdadeira, p. 47. 
A partir do diálogo estabelecido entre Antonio Tabucchi e Xavier Janata Monroy, temos uma intrigante reflexão sobre Noturno Indiano. O conto "A frase a seguir é falsa. A frase anterior é verdadeira" consiste em uma discussão sobre o romance em questão, em que os interlocutores debatem sobre a temática e o conteúdo do livro.

Ao tecer suas considerações sobre Noturno Indiano, o teósofo de Madras sugere que a chave para a compreensão do romance está em seu último capítulo. Segundo Xavier Monroy, esse trecho foi mal-interpretado pela cultura ocidental. Sob o ponto de vista do teósofo de Madras, Noturno Indiano deve ser lido a partir de um olhar oriental, afirmando ser seu autor um profundo conhecedor do hinduísmo Antonio Tabucchi, por sua vez, nega que conheça o mandal (representação do símbolo da totalidade e da circularidade na religião hinduísta) e humildemente observa que seu interlocutor atribui um significado a seu romance muito maior daquele pretendido pelo autor.

Ao criar esse embate entre os interlocutores, Antonio Tabucchi desconstrói a crítica sobre seu romance, já que, ao mesmo tempo em que corrobora com uma leitura considerada ocidental, a qual se volta para a questão do duplo, dos espelhos e do jogo, aponta para outras leituras possíveis, como a relação de Noturno Indiano com o hinduísmo. Com isso, o escritor italiano coloca seu texto em aberto a várias interpretações. Verificamos, portanto, que Antonio Tabucchi nos envolve em um jogo intrincado, no qual nos dá uma informação apenas para negá-la logo em seguida, não nos sendo possível afirmar que um dos posicionamentos seja verdadeiro e o outro falso. Percebemos que, a todo o momento, o escritor italiano cria e destrói, faz e desfaz, sendo justamente esse movimento um dos traços característicos de sua obra.

Como parte desse jogo, o teósofo de Madras insiste em afirmar a relação entre o sentido intrínseco à narrativa de Noturno Indiano e a cultura hinduísta. Para isso, tece uma explicação para o mandala, salientando que este representaria o "globo" ou "anel", os quais podem ser metaforizados, segundo sua cultura, pelo "zero" e pelo "espelho". Assim, explica que, segundo a concepção indiana, o zero simboliza o Brama e o Nirvana, sendo "matriz do todo e do nada, luz e treva"19. Em relação ao espelho, o teósofo de Madras apresenta um intrigante comentário que discorre sobre os efeitos de um jogo criado a partir de uma combinação de reflexos:

Tomemos, portanto, um espelho na mão e olhemos. Esse nos reflete idênticos invertendo as partes. O que está à direita se transpõe à esquerda e vice-versa, de modo que quem nos olha somos nós, mas não os mesmos nós que um outro vê. Restituindo-nos a nossa imagem invertida no eixo frente-costas, o
19. TABUCCHI. A frase a seguir é falsa. A frase anterior é verdadeira, p. 51. 
20. TABUCCHI, 2003b:51

21. TABUCCHI. A frase a seguir é falsa. A frase anterior é verdadeira, p. 53

22. TABUCCHI. A frase a segui é falsa. A frase anterior é verdadeira, p. 58 espelho produz um efeito que poderá até aludir a um sortilégio: olha-nos de fora, mas é como se nos examinasse por dentro, a nossa própria visão não nos é indiferente, intriga-nos e perturba-nos mais que a de qualquer outra pessoa. Os filósofos taoístas chamam-na de $o$ olhar devolvido. ${ }^{20}$

Essa divergência de posicionamentos cria certa tensão no diálogo travado entre Tabucchi e Xavier. No entanto, no momento em que o leitor está praticamente convencido da veracidade das palavras de Tabucchi, este, nas linhas finais de sua segunda carta, adverte o teósofo de que "os escritores são, frequentemente, pessoas nas quais não podemos confiar"21. Essa afirmação corrobora a suspeita de que Xavier Monroy poderia ter razão em seu argumento, negado por Tabucchi. No entanto, o diálogo não propõe que um dos interlocutores esteja certo e o outro errado, ou que Antonio Tabucchi mente ou diz a verdade ao afirmar que não conhece a cultura indiana.

Essa ambiguidade está manifesta no próprio título do conto, o qual contém uma afirmação que anula a si mesma, já que as duas sentenças de que é composta são a imagem especular uma da outra, sendo a primeira o reverso da segunda e vice-versa, ambas fechando-se em um círculo. Como afirm Xavier Monroy, "é uma cobra que morde a própria cauda"22. Não nos é possível, portanto, julgar tal afirmação como verdadeira ou falsa, já que esta admite ambas as possibilidades ao mesmo tempo. O que temos nesse conto são, mais uma vez, a dúvida, a incerteza e a inversão de ideias.

Partindo desses elementos, pode-se constatar, portanto, que o escritor italiano problematiza o conceito de "verdade" em suas obras. Utilizando-se do paradoxo presente no título do referido conto, Antonio Tabucchi questiona a dicotomia lógica segundo a qual uma afirmação deve ser necessariamente verdadeira ou falsa, postulando a inexistência de uma "verdade” única e imutável.

Em Antonio Tabucchi, a linha que separa o real e a ficção é, às vezes, muito tênue. Existe em sua obra um constante jogo entre essas duas instâncias, o que faz com que o leitor se pergunte o tempo todo o que é real e o que é ficção. Sobre a relação entre texto e autobiografia, Tabucchi se pergunta quanto da vida do escritor permanece em seus escritos e comenta que "con questo dobbiamo venire alla noiosa questione della verità, che in letteratura non significa niente, perché la letteratura è una realtà parallela"23.

No livro $A$ invenção da verdade, Olímpio Pimenta aborda o mesmo problema ao refletir sobre as obras de Nietzsche e Mann os quais questionam a ideia da existência de uma verdade definitiva e transcendental ao mesmo tempo em que reorientam "a pesquisa da verdade sob a direção da criação e da incorporação"24. Seguindo essa linha de pensamento, esses autores negam
23. TABUCCHI. Autobiografie Altrui, p. 98. "Com isso devemos entra na tediosa questão da verdade, que em literatura não significa nada, porque a literatura é uma realidade paralela." (Tradução nossa).

\section{PIMENTA. $A$ invenção da} verdade, p. 125
EM TESE
BELO HORIZONTE
v. 19
N. 3
SET.-DEZ. 2013
TORRE. 0 jogo entre real e ficcional em Antonio Tabucchi
P. $148-158$ 
o caráter imutável e definitivo da "verdade" e sua superioridade em relação ao falso. Pimenta segue explicitando que

isso não se dá em nome de um discurso ainda mais verdadeiro que eles estariam proferindo, mas justamente através $\mathrm{d}$ uma mudança de perspectiva que despoja a verdade de uma superioridade de princípio em relação ao erro ou ao falso. E o espaço clássico da verdade que é posto em xeque a favor da introdução de um registro distinto para seu processo - nomeadamente, o registro da ficção. ${ }^{25}$

Como nos lembra Anna Dolfi (2006), o problema posto por Antonio Tabucchi nos remete à clássica charada que conta a história de um prisioneiro que está dentro de uma cela na qual se abrem duas portas, sendo que cada uma delas é guardada por uma sentinela. Uma das sentinelas diz somente a verdade, enquanto a outra sempre mente. Uma das portas conduz à liberdade, ao passo que a outra leva o prisioneiro à morte. Este poderá fazer apenas uma pergunta a uma das sentinelas na tentativa de se salvar. Assim, basta que o prisioneiro pergunte a qualquer das sentinelas qua porta a outra sentinela indicaria como aquela da salvação e, após a indicação, escolher a saída contrária. O prisioneiro deve tomar essa atitude porque, em ambos os casos, a sentinela indicará a porta que o conduzirá à morte. É preciso, pois, percorrer o caminho inverso àquele obtido através da resposta da sentinela para que, neste caso, se possa alcançar a salvação. ${ }^{26}$

Essa constatação está relacionada à concepção tabucchiana de "jogo do reverso", segundo a qual o movimento de inversão é um artifício que nos permite partir das aparências e conjugá-las com seu reverso de forma intersticial, de modo que o que está na sombra possa ser iluminado. Segundo Antonio Tabucchi (2006), "il gioco del rovescio è in sostanza il sospetto che esista nel reale un'altra faccia della medaglia, cioè che il reale si mostri in un aspetto che è immediatamente conoscibile e che celi un altro aspetto, che è forse quello più vero, ma che rimane in ombra" 27

Nesse sentido, o "jogo do reverso" nos instrui a repercorrer o labirinto em sentido contrário na tentativa de vislumbrarmos outras realidades possíveis. Isso é o que faz Roux no último capítulo de Noturno Indiano, ao subverter a ordem, colocando-se no lugar do outro no momento em que reconta sua própria trajetória. Porém, nesse caso, o enigma não se resolve, permanecendo sem soluções. Como ressaltado anteriormente, na obra de Antonio Tabucchi, não existe certo ou errado, verdadeiro ou falso, como o paradoxo presente no título do conto epistolar "A frase a seguir é falsa. A frase anterior é verdadeira”, o qual nos prende em um labirinto sem fim, já que ao saltarmos de uma frase para a outra, es tamos, na verdade, percorrendo o caminho inverso àquele
26. cf. DOLFI, 2006:62-63.

27. TABUCCHI apud DOLFI. Tabucchi: la specularità, il rimorso, p. 69. “O jogo do reverso é em substância a suspeita de que exista no real uma outra face da medalha, isto , que o real se mostre em um econ outro aspecto, que tavez seja aquele mais verdadeiro, sejas que permanece na (Tradução nossa). 
fornecido anteriormente, o que faz com que sempre voltemos ao mesmo lugar, ou seja, à dimensão da incerteza ou da certeza do paradoxo.

\section{REFERÊNCIAS}

ALVES, Sérgio Afonso Gonçalves. Fios da memória, jogo textua

e ficcional de Haroldo Maranhão. 2006. 233 f. Tese (Doutorado

em Letras - Literatura Comparada) - Faculdade de Letras,

Universidade Federal de Minas Gerais, Belo Horizonte, 2006.

ARRIGUCCI JUNIOR, David. O escorpião encalacrado. São Paulo: Perspectiva, 1973.

DOLFI, Anna. Tabucchi: la specularità, il rimorso. Roma: Bulzoni, 2006.

PERRONE-MOISÉS, Leyla. Lição de casa. In: BARTHES, Roland. Aula. São Paulo: Cultrix, 2002. p. 49-89.

PIMENTA, Olímpio. A invenção da verdade. Belo Horizonte: Editora UFMG, 1999.

TABUCCHI, Antonio. Autobiografie altrui: poetiche a posteriori. Milano: Universale Economica Feltrinelli, 2003a.

TABUCCHI, Antonio. A frase a seguir é falsa. A frase anterior é verdadeira. In: $\mathrm{TAB} \cup C \mathrm{CHI}$, Antonio. Os voláteis do beato Angélico. Trad. Ana Lucia Belardinelli. Rio de Janeiro: Rocco, 2003b. p. 47-59.

TABUCCHI, Antonio. Noturno Indiano. Trad. Wander Melo Miranda. Rio de Janeiro: Rocco, 1991. 